\title{
PENÍNSULA: SU BAUTISMO
}

\author{
Adrián Curiel Rivera \\ Director del CEPHCIS, UNAM
}

Hace ya diez años, antes de que la Unidad Académica en Ciencias Sociales y Humanidades se transformara en el actual Centro Peninsular en Humanidades y en Ciencias Sociales, un grupo de universitarios, convocados por el doctor Mario Humberto Ruz Sosa, nos reunimos para discutir acerca de la necesidad de crear un órgano que representara los intereses profesionales y las líneas de investigación de nuestra entonces bastante joven comunidad académica. La idea de crear una revista que dotara de voz a la nueva sede de la UnAm en Mérida, y que cumpliera con los estándares de calidad y periodicidad exigibles a las publicaciones de ese tipo que ya existían, se impuso desde el principio como un desiderátum y una exigencia en el marco de las actividades de extensión académica impulsadas por el Subsistema de Humanidades. Materializar ese proyecto parecía, al mismo tiempo, lo más sencillo y complicado del mundo. Estábamos de acuerdo y queríamos hacerlo: una revista. Pero ¿cómo empezar? ¿A qué autores invitaríamos a colaborar, y cómo convencer a figuras de primer nivel para que nos entregaran un artículo original? ¿Y los dictaminadores, cómo los seduciríamos, por así decir, para que dedicaran horas de su valioso tiempo a cambio de la simple promesa de que su participación sería imprescindible para consolidar nuestra aventura? ¿Y cómo bautizaríamos a la revista? En este punto, surgió un constructivo debate. ¿Debíamos centrarnos, para encontrar un nombre adecuado, en los planteamientos teóricos y metodológicos de las disciplinas representadas por cada uno de los investigadores? ¿No sería mejor hacer hincapié en el carácter inter o multidisciplinario de una entidad caracterizada por su pluralidad de enfoques? ¿Y si comenzábamos por lo más obvio, es decir, el espacio material que, en tanto seres humanos, habitábamos para llevar a cabo nuestros empeños: la Península de Yucatán?

Como se sabe, a diferencia de la isla o el archipiélago, la península está mayor pero no totalmente rodeada de mar. Por tanto, el viaje tierra adentro es tan factible como la exploración marina desde la costa. Horizontes interiores y horizontes allende los océanos. Ése era el espíritu editorial que gobernaba los trabajos de aquella embrionaria mesa de redacción, literalmente un escritorio alrededor del cual se acordó en democracia que la revista que haríamos desde la Península de Yucatán, y que 
PENÍNSULA

hablaría de esa geografía pero también de muchas otras — contiguas y lejanas — se llamaría, precisamente, Península.

Con el tiempo, muchos de los problemas para mantener con vida y saludable a una revista se han podido solventar. Con el tiempo, Península ha podido seguir siendo Peninsula. Sirvan estas condensadas líneas para conmemorar sus primeros diez ańos y como público reconocimiento a todos aquellos que han trabajado con ahínco para que el sueño inicial de la revista sea hoy una realidad. 